\title{
Morphological study of the Larynx of the indigenous adult Male Pigeon (Columba domestica)
}

\author{
H. K. N. AL-Mhanna \\ Coll. of Vet. Med./ unive of Al-Kufa
}

Abstract

Formalistic study elucidate that the larynx in the fourteen healthy indigenous male pigeons (Columba domestica) for benefit in the study of the respiratory physiology, histopathology, and the respiratory diseases analyzes. After bird's preparation, the larynx detected, and then the shape, position and its components studied in details. The larynx emerges in the caudal part of the oropharyngeal cavity as a heart-shaped cartilaginous mass. It composed of a single hyaline cricoid cartilage which consisted of body and left and right wings, double hyaline arytenoid cartilages which consisting of body and rostral and caudal processes, and single hyaline procricoid cartilage which consisted of body dorsally and curved tail caudoventrally. These cartilaginous components surrounded by laryngeal skeletal muscles intrinsic (superficial and deep) and extrinsic (rostral, caudolateral, and caudomedial).

Keys words: Larynx, Males and Indigenous Pigeon.

\section{Introduction}

Avian respiratory system definitely diverse from mammals grossly, physiologically, and mechanics, the larynx which does not have vocal cords, therefore is not involved in voice production and epiglottis is not present (1).Larynx in Birds like (chicken, turkey (Meleagris gallopava), and long-legged buzzard (Buteo rufinus)) was elevated obviously into the caudal part of the floor of the oropharynx as hill named laryngeal mound (mons laryngealis) appear as heart-shaped apex rostrally extend from the base of the skull into base of the tongue. This mound contains respiratory opening (inlet or glottis) (2, 3, 4, and 5). However, laryngeal mound is roughly triangular in the West African guinea fowl (Numida meleagris galeata) (6), in ostriches, there is no mound and larynx project from the pharynx (7).Laryngeal glottis in domestic fowl (Gallus gallus var. domesticus), and ostriches appear as slit-like opening restricted by the arytenoid cartilages, and extend caudally as narrow continuous caudally by narrow furrow called the laryngeal fissure (sulcus larynges) (8, 9, 7).In chicken and long legged buzzard, the laryngeal mound bears four rows of caudally pointing cornefied papillae onto each side, which appear as large rostral and short caudal transverse rows, and two sagittal rows of 5-6 small papillae found on the lateral and medial borders of the caudal arytenoid process $(10,2,4)$. While in ostriches the papillae are not visualize (7). In avian the largest laryngeal cartilage is cricoid cartilage, which is single and hyaline type. Consist of body and the left, and right wings united laterally by a thin line of flexible cartilage. The body is gutter-like plate, concave dorsally, extend rostrally as shovel-like flexible cartilage, in the median of body contain dorsally ossified projection ridge. The medial border of each wing articulates with the procricoid cartilage forming procricocricoid synovial joint (11, 12). The cricoid cartilage in turkeys is much shorter than that in the chicken rostrocaudally, ending rostrally at the level of the rostral tip of the arytenoid cartilages $(10,5) . I n$ songbirds and passerine species (Corvus corax, C. orru, and $C$. brachyrhynchos) the cricoid wings are separate as dorsal cricoid cartilages, and rod like cartilages $(2,8)$.In passerine species (several Corvids), non-passerine species (Columba, spheniscids, and Gallus), chicken, turkey, and long-legged buzzard, 


\section{$\begin{array}{llll}\text { AL-Qadisiya Journal of Vet.Med.Sci. } & \text { Vol./12 } & \text { No./1 }\end{array}$}

the smaller laryngeal cartilage is Procricoid cartilage, which is single and hyaline type appear as comma-shaped composed of head dorsally and tail ventrally, mediated between arytenoid cartilages, and cricoid wings. Head contain left and right laterodorsal facets, which articulated with the bodies of arytenoid cartilages form the procricoarytenoid synovial joints. The tail has left and right lateral facets, which articulate with cricoid wings (10, 8, 4).In chicken, duck, turkey and long-legged buzzard the roof of the larynx constituted by paired and hyaline type laryngeal cartilages they meet together dorsocaudally. It consists of the body, the rostral process extends to the oral end of cricoid cartilage, and the caudal process is free end $(8,4)$. In ratites and penguins, the arytenoids caudal process variable or absent. (8)In Columba, spheniscids, Gallus, and stix the arytenocricoid ligament connected the rostral process and body of arytenoid cartilage with body and wings of cricoid cartilage $(12,10)$. In Corvids, aryteno-cricoid dorsalis ligament continued caudally between arytenoid body and the dorsal cricoid cartilage (8), in chicken and Corvus brachyrhynchos (passerine species) Aryteno-arytenoid

\section{Materials and methods}

The present study was second-hand fourteen male pigeon which accumulated from the markets of Al-Diwanyia city, and then reserved for fourteen days to emphasize bird's innocuousness. Specimens were preparing by injection of an intramuscular ketamine $(50 \mathrm{mg} \mathrm{kg})$ and xylazine $(20 \mathrm{mg}$ $\mathrm{kg}$ ) (5), for anaesthetized, then opened thoracoabdominal cavity and well bleeding by puncher of the heart at the right atrium. Larynx observed immediately after prepared, described the position and shape and relation shipped with other oral cavity structures ligament (intraarytenoid ligament) connected between the right and left arytenoid cartilages at the body and caudal process $(10,8)$.In birds like bursa roller pigeon (Columba livia) and chicken, laryngeal muscles comprise extrinsic and intrinsic laryngeal muscles. Extrinsic type consists of rostral extrinsic muscles paired muscles; extend from the dorsal surface of the rostral basibrachial bone of the hyoid rostrally to the larynx caudally. The caudolateral extrinsic muscles paired, arise from composite tracheal muscle and mainly inserted into the dorsal mass and into the body and wing of cricoid cartilage. In addition, the caudomedial extrinsic muscle is unpaired muscle that arises from composite tracheal muscle and inserts onto the ventral surface of the cricoid body $(10,8)$. While intrinsic laryngeal muscles are superficial and deep muscles. The superficial type extends from the wing and body of cricoid cartilage to the arytenoid cartilage, while the deep muscle horse-shoes-shape consist of three division medial, middle, and lateral, which runs from caudal midline of the larynx to the cricoid and arytenoids cartilages $(8,4)$. studied in details, then carefully removed, fine dissections immediately to determine the different segments of the laryngeal cartilages(5). Moreover, by using (vernier, ruler, amplifier lens (X12, X6)) registered the following data:

1- Length and width of laryngeal glottis

2- Length of the dorsal laryngeal fissure.

In addition, for purposes of photography used Sony W230 digital camera 12.1 Mega pixels. Finally, results presented as mean \pm SE.

\section{Results}

At the beginning of the neck and base of the head protrudes the cartilaginous mass (larynx) that in the caudal part of the oropharyngeal cavity. It is come into view as heart-shaped its apex toward rostrally and base toward caudally continued with trachea. 
At the median of the laryngeal mound there is split-like opening called laryngeal inlet (glottis) which limited by the medial margins of the dorsal borders of the arytenoid cartilages that continued caudally as the very narrow of the longitudinal fissure (Fig. 1). The mean length of glottis and laryngeal fissure was $(0.7 \pm 0.1 \mathrm{~cm})$ and $(0.3 \pm 0.05 \mathrm{~cm})$ respectively. On the oral aspects there are several papillae varied in size and position

1- The caudal group: - left and right curved lines of long caudally pointed papillae started from the caudal process of the arytenoid cartilages to the ventral part of the cricoid cartilage, and the sagittal line of caudally pointed papillae between preceding which started from the caudal process of the arytenoid cartilage to the ventral border of the cricoid cartilage (Fig. 1).

2- Marginal group: - Left and right short papillae arranged along the glottic margins (Fig.1).

\section{Laryngeal cartilages}

There are three types of the laryngeal cartilages which hyaline type:

1- Cricoid cartilage: - unpaired cartilage represent the strong base of the larynx consist of body which convex from the ventral surface and concave from the dorsal surface. It was extend as rostral gutter-like extension and extend dorsocaudally as left and right wing-like extensions. At the medial aspect of the dorsal part of the wings there is articulating facet which articulates with the lateral facet of the tail of the procricoid cartilage formed the procricocricoid joint. (Fig. 2,3)

\section{2- Procricoid cartilage:-}

Unpaired very small cartilage represented a median short-tack lie at the caudal portion of the larynx that consisted of body dorsally and tail ventrally. Body of procricoid cartilage contained right and left dorsolateral facets to articulate with the bodies of arytenoid cartilages at the right and left ventromedial facets forming procricoarytenoid joint (Fig. 3).

\section{3- Arytenoid cartilages:-}

Appeared as left and right hyaline cartilages meeting together caudally, acting as ceiling of the larynx and limiting of the glottis, each one consisting of body which characterized by contain narrow groove restricted by the dorsal and ventral borders at the lateral surface, ventromedial articulated facet to articulation with procricoid cartilage at the caudal part, rostral process extended parallel with the rostral extending of cricoid cartilage, and caudal process which enveloped by group one of laryngeal papillae (Fig. 2,3).

\section{Laryngeal Muscles:}

1- Intrinsic laryngeal muscles:

a- Superficial intrinsic muscles:- they left and right of skeletal muscles under the mucosa of the dorsal surface of the laryngeal mound appear as twisting straps the broad origin from the caudal aspect of the larynx along base of the caudal laryngeal papillae and the narrow insertion ventral aspect of the cricoid cartilage. (Fig. 1).

b- Deep intrinsic muscles:- they broad paired muscles, they furnished the lateral aspect of arytenoid and cricoid-wing. Lie under the previous muscles, gave the laryngeal mound rounded appearance arise from the caudal aspect of the cricoid wings at its junction with the procricoid cartilage and inserted on the cranial aspect of the arytenoid cartilages, its muscle fibers extend rostrocaudally, the dorsal limited of this muscle attached along dorsal border of the lateral arytenoid groove while its limited ventrally at the junction line of the cricoid body with cricoid wing. (Fig. 1).

\section{2- Extrinsic muscles:-}

1- Rostral extrinsic muscles:- they paired, arose from the ventral surface of the cricoid body, and inserted in the rostral basibrachial bone of the hyoid bone.

\section{2- The caudolateral extrinsic muscles:-} they paired arose mainly from sternotrachealis muscle, and inserted on the lateral edge of the ventral surface of the body of the cricoid cartilage. 


\section{$\begin{array}{llll}\text { AL-Qadisiya Journal of Vet.Med.Sci. } \quad \text { Vol./12 } & \text { No./1 }\end{array}$}

Laryngeal ligaments:

1- Crico-artynoid ligaments: It was paired broad membranes connected along the ventral border of the arytenoid cartilage and along the rostral border of the wing of the cricoid cartilage (Fig. 2).

2- Interarytenoid ligament: It was small ligament connected the right and left arytenoid cartilages at the caudal midline dorsal to the procricoarytenoid joints (Fig. 2).
3-Aryteno-glossal ligament: It was thick ligament attached the rostral processes of arytenoid cartilages and the paraglossal bone of the tongue parallel with rostral extrinsic muscles.

4- Crico-tracheal ligament: connected the caudal border of the cricoid cartilage (body and wings) with the rostral border of the first tracheal ring.

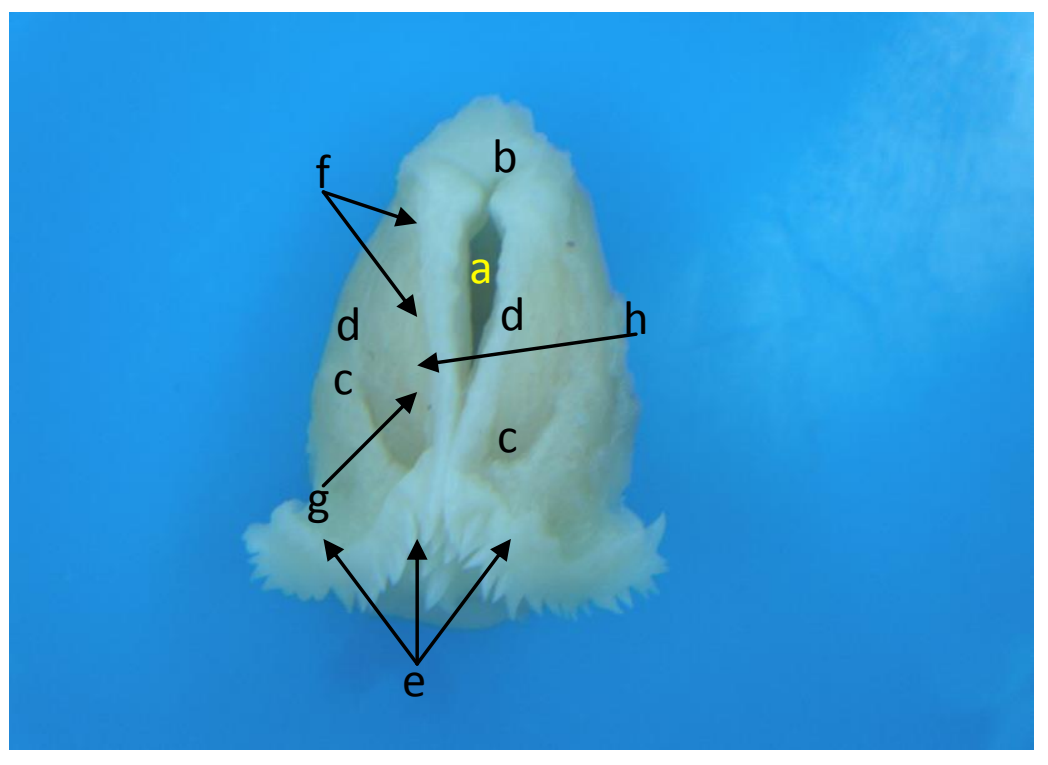

Fig. (1): Larynx of the Pigeon (dorsal view) after mucous membrane as removed demonstrating: the heart-shaped of laryngeal mound, laryngeal glottis (a) rostral gutter-like extension of the cricoid cartilage (b), superficial intrinsic muscles (left \& right) (c), Deep intrinsic muscles (left \& right) (d), caudal group of the laryngeal papillae (e), marginal group of the laryngeal papillae (f), laryngeal fissure $(\mathrm{g})$, interarytenoid ligament $(\mathrm{h})$. 


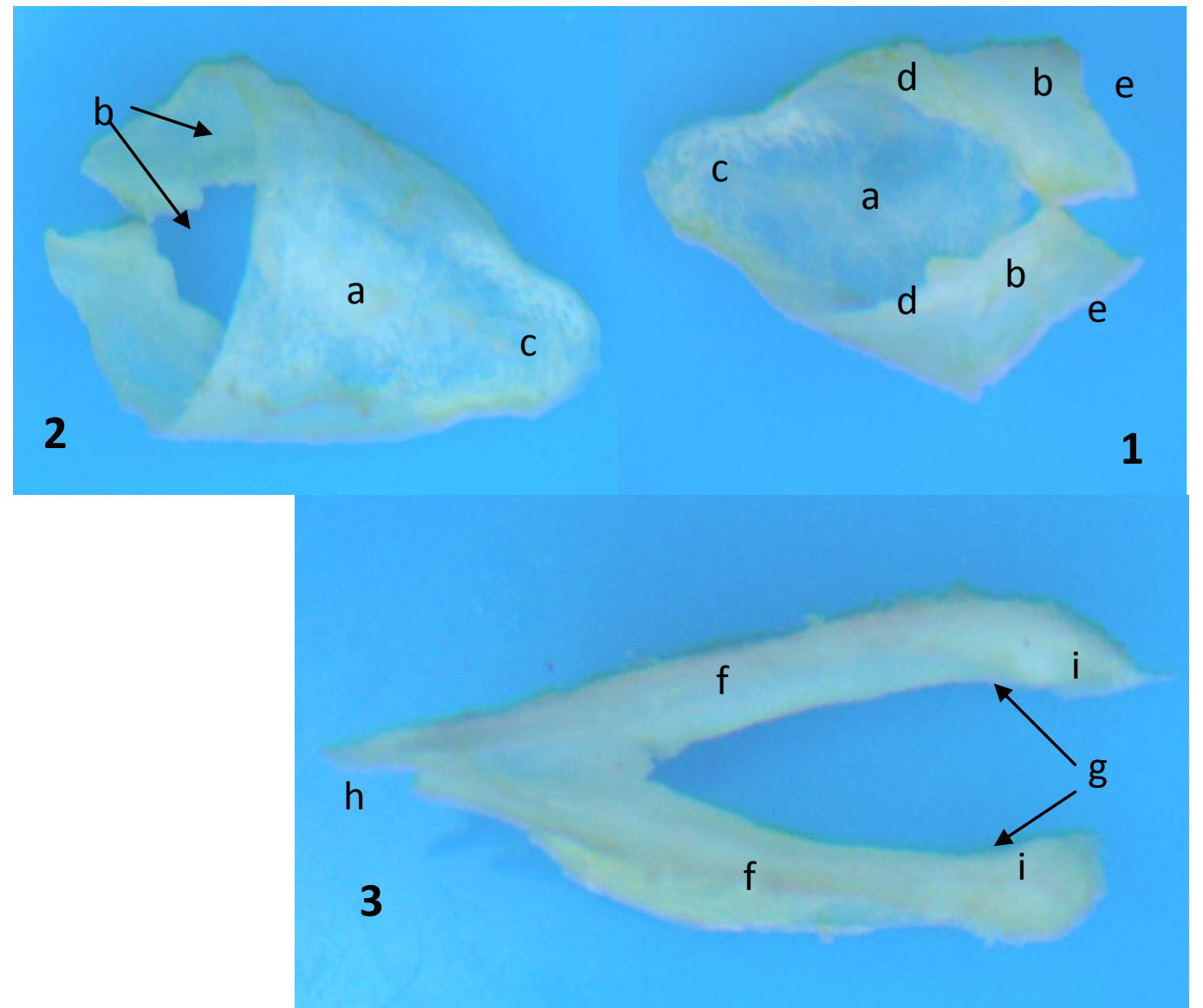

Fig. (2): Magnified laryngeal cartilages of the Pigeon: cricoid cartilages (dorsal (1) \& ventral (2) view) and arytenoid cartilage (ventral view (3)) showing: cricoid body (a), cricoid wings (b), rostral extending of the cricoid body (c), rostral borders of the cricoid wings (d), caudal borders of the cricoid wings (e), body of arytenoid cartilage(f), ventromedial articulated facet articulation with procricoid cartilage (g), rostral process (h), caudal process (i) .

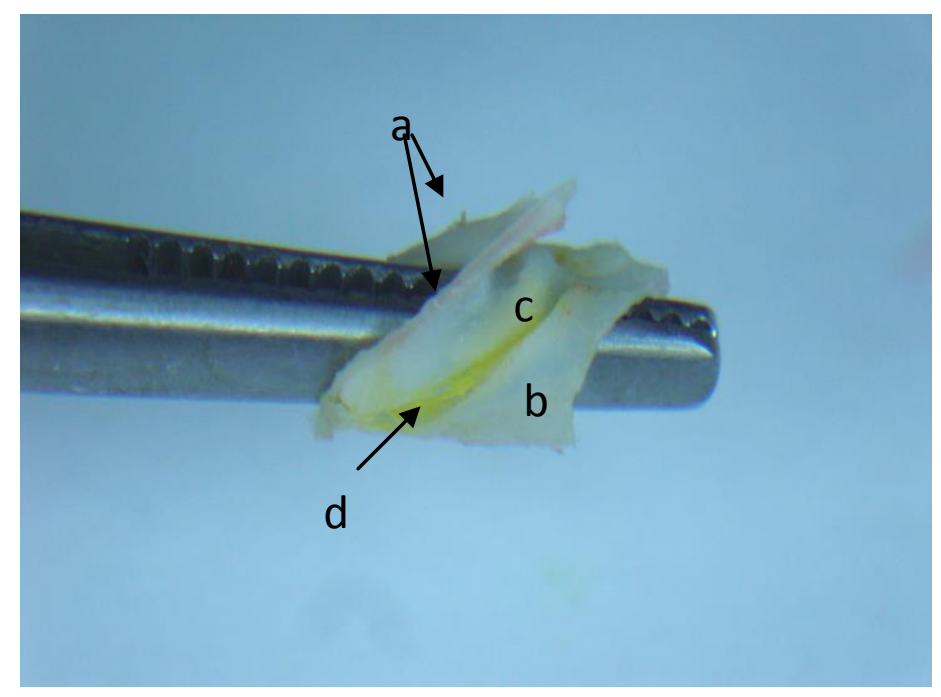

Fig. (3): Laryngeal cartilages of the Pigeon (lateral view) after mucous membrane and laryngeal muscles as removed demonstrating: Arytenoid cartilages(a), left wing of cricoid cartilage (b), procricoid cartilage(c), Crico-artynoid ligaments (d). 


\section{Discussion}

The laryngeal mound appeared heartshaped. These results were agreed to the findings (2); (3); and (4) in the chicken, turkey, and long-legged buzzard, and uncorresponding with, (6) who portrayed it as roughly triangular in the west african guinea fowl, (10) who said it was relatively elongated lozenge in duck and goose.The laryngeal glottis appeared as slit-like opening which bounded by dorsal borders of the arytenoid cartilages and incessant caudally as narrow fissure, these consequence fully confirmed with (8); and (4) in domestic fowl. But (6); (7); and (13) elucidated this fissure look as an inverted triangular shape in the west african guinea fowl and ostriches. The laryngeal glottis can be thought of as a valve atop the lungs which can prevent the entering foreign matter like food or water into the lungs $(2 ; 14 ; 7$; and $15)$.The dimensions of the respiratory organs are different in birds species because body's size are different, these based on the different life environments. This fact are guide to why the mean length and width of glottis in the pigeon in our study unlike in a typical male chicken the length was about $(1.1 \mathrm{~cm})$, in turkey length and width were $(1.5 \mathrm{~cm})$ and $(0.5 \mathrm{~cm})$ respectively, while in duck and goose was $(1.3 \mathrm{~cm})$ and $(0.3 \mathrm{~cm} \pm$ $0.1)$ respectively (10), additional to that these dimensions of the glottis in long legged buzzard was very close was $(0.9 \mathrm{~cm})$ and $(0.186 \mathrm{~cm})$ respectively (4), (7) addition the large gap in length between target birds in our study with the ostriches which was $(3.33 \pm 0.75 \mathrm{~cm})$. The laryngeal papillae on the initial part of the esophagus have a mechanical functions such as quickly deglutition of the grains toward the esophagus $(2$, and 14,5$)$. The arrangements of these papillae are very varies among bird species, the caudal group of the pigeon in our study, in turkey ,arrange as two rows of caudomedial direction without marginal papillae (5). The marginal papillae, in the chicken, goose and long legged buzzard, are replaced by the one or two sagittal rows of caudally pointed papillae $(10 ; 2$; and 4$)$, while in pigeons in this study coordinated with (2); and (5) who said no sagittal line in turkey. While (7) said the papillae were not visualized on the larynx in ostriches.The hardness base of the larynx represented by the ligaments and muscles attachments the cricoid cartilages, it is not complete circle as in the domestic animals but have ventral or base part (body) and dorsal part or (two wings) separated by cartilaginous line. And it does not have median mucosal ridge at the median plain of the dorsal surface of the cricoid cartilage. These consequences well matched with (10); (12); and (3) they showed similar results in the domestic fowl, duck, and Spheniscidae, but they have median mucosal ridge, and uncorresponding with (8) explained that the body and it is rostral process were incomplete in the columba and corvus, (2) and (8) said the cricoid wings were separated as dorsal cricoid cartilages, and rod like cartilages in songbirds, Corvus corax, C. orru, and $C$. brachyrhynchos. The connective part of the laryngeal cartilages by the joints represented by the very small hyaline cartilage called procricoid, which linkage the arytenoid and cricoid cartilages caudally, this shape consensus with (8); and (4) in chicken, Columba, and long-legged buzzard. It is similar to that the procricoid of the turkey, but its smaller and it is tail curved (5), moreover (8) clarified that the procricoid body was cuboidal or spherical shape and the tail was absent in Corvus., and (7) reported that in ostriches had not procricoid cartilage. The morphological structures of the arytenoid cartilages in pigeon in this study were agreed with (8); (2); and (4) in chicken, duck, turkey and long-legged buzzard, and disagreed with, (10) said the arytenoid caudal process absent in ratites and penguins, and with (7) noticed the arytenoid cartilages consisted of rostral (elongated), middle (circular) and caudal (hemisphere) 
processes in the ostriches.Laryngeal muscles were paired muscles connecting the laryngeal cartilages together and with the other structures they act as dilator and contraction of the laryngeal glottis as in all birds such as turkey, chicken, Corvus brachyrhynchos, and Long-Legged Buzzard $(5,10 ; 8$; and 4$)$ but there is no caudomedial muscles, while un coincided with, (8) who said constrictor muscles of the laryngeal glottis composed of five discrete muscles in Columba and Corvus species and three discrete muscles in (Corvus brachyrhynchos),Laryngeal ligaments were represented by four types, the right and left artyno-cricoid ligaments were connected between body of arytenoid cartilage and wing of cricoid cartilages. This result inconsistence with (8); and (10) in nonpasserine (spheniscids, Gallus, Columba, and stix), this ligament linked between rostral process, body of arytenoid cartilage and body and wings of cricoid cartilage, (8) said, in Corvids (passerine species), this ligament named aryteno-cricoid dorsalis ligament was continued caudally between arytenoid body and the dorsal cricoid cartilage, and (10) showed, in chicken, this ligament named caudal crico-arytenoid ligament.

\section{References}

1. Pesek, L. (2000): The avian respiratory system. Winged Wisdom Pet Bird Magazine 1: 1-3

2. McLelland, J., (1990): A Colour Atlas of Avian Anatomy. Wolfe Publishing Ltd. Eng. PP. 95-119

3. Bacha, W.J., and Bacha, L.M. (2000): Color Atlas of Veterinary Histology 2nd (ed.): Lippincott Williams \& Wilkins. PP: 175-190

4. Kabak, M., Orhan, I.O., and Haziroglu, R.M. (2007): The gross anatomy of larynx, trachea, and syrinx in the Long-Legged Buzzard (Buteo rufinus). Ana. Histo. Ember. 36 (1): 27-32.

5. AL-Mussawy, A.M.M. (2011): Anatomical and Histological Study of Major Respiratory Organs (Larynx, Trachea, Syrinx, Bronchi and Lungs) In Indigenous Male Turkey (Meleagris gallopava). M.S. Thesis. AL-Qadisiya Uni. Vet. Med. College.

6. Lbe, C.S., Onyeanusi, B.I., Salami, S.O., Umosen, A.D., and Maidawa, S.M. (2008): Studies of the major respiratory pathways of the West african guinea fowl (Numida meleagris galeata): The Morphometric and Macroscopic
Aspects. Inter. J. of Poul. Sci. 7 (10): 997-1000

7. Tadjalli, M., Mansouri, S. H., and Poostpasand, A. (2008): Gross anatomy of the oropharyngeal cavity in the ostrich (Struthio camelus). Iranian J. of Vet. Resear., Shiraz Univ. 9 (4): 316-322

8. Baumel, J.J., King, A.S., Breazile, J.E., Evans, H.E., and Vandan Berge, J.C. (1993): Respiratory system. In: Hand book of Avian Anatomy Nomina Anatomica Avium 2nd (ed.): Club. Cambridge, Massachusetts. PP: 257-299

9. Swenson, M.J. (2004): Ducks Physiology of Domestic Animals. ( $9^{\text {th }}$ (ed.): Darya. Garya. Ganj. New Delhi. PP: 203

10. Getty, R. (1975): Anatomy of domestic animals. W.S. Saunders Co. Philadelphia. PP: 1884-1917

11. Hogg, D.A. (1982): Ossification of the laryngeal, tracheal and syringeal cartilages in the domestic fowl. $J$. Anat. 134 (1): 57-71

12. Brown, R.E., Brain, J.D., and Wang, N. (1997): The avian respiratory system: A unique model for studies of respiratory toxicosis and for monitoring air quality. Environ Health Perspect (105):188-200 
$\begin{array}{llll}\text { AL-Qadisiya Journal of Vet.Med.Sci. } & \text { Vol./12 } & \text { No./1 }\end{array}$

13. Frandson, R.D., Wilke, W.L., and Fails, A.D. (2009): Anatomy and Physiology of Farm Animals $7^{\text {th }}$ (ed.): Wiley-Black Well. PP. 471474

14. Fitch, W.T.S. (1994): Vocal Tract Length Perception and the
Evolution of Language. PhD. Thesis. Brown Uni. B.A. Biol. PP. $1-95$

15. Smallwood, J.E. (2010): Selected topics in avian anatomy. Wildlife Rehabilitators of North Carolina. PP: $1-24$

\title{
دراسة شكلية لحنجرة ذكور الحمام البالغة المحلية(Columba domestica)
}

\author{
حازم كريم ناصر المحنة \\ كلية الطب البيطري/جامعة الكوفة ناصنة \\ الخلاصة
}

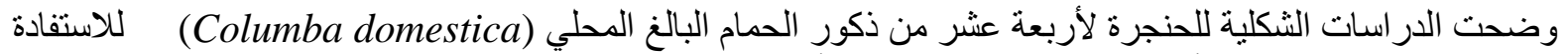

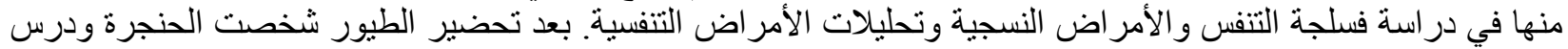

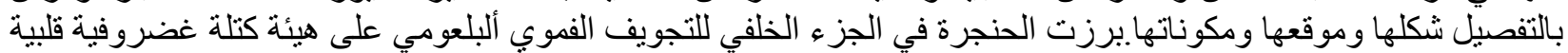

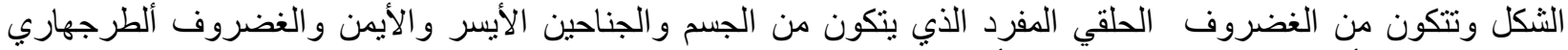

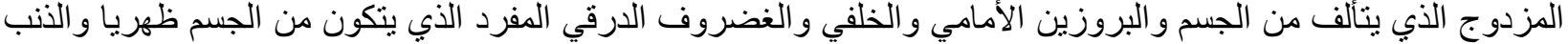
المقوس خلفيا ظهريا. هذه المكونات الغضروفية للحنجرة محاطة بالعضلات الهيكلية الحنجرية الداخلية (السطحية والغائرة) والخارجية (الأمامية والخلفية الوحشية والفية والخلفية الأنيسة). الكلمات الافتتاحية (الحنجرة، الذكور ، الحمام المحلي) 